\title{
ECLSS and Thermal Systems Integration Challenges Across the Constellation Architecture
}

\author{
Robyn L. Carrasquillo ${ }^{1}$ \\ NASA Marshall Space Flight Center, Huntsville, AL, 35812 \\ David E. Williams ${ }^{2}$ \\ NASA Johnson Space Center, Houston, TX 77058
}

\begin{abstract}
As the Constellation Program completes its initial capability Preliminary Design Review milestone for the Initial Capability phase, systems engineering of the Environmental Control and Life Support (ECLS) and Thermal Systems for the various architecture elements has progressed from the requirements to design phase. As designs have matured for the Ares, Orion, Ground Systems, and Extravehicular (EVA) System, a number of integration challenges have arisen requiring analyses and trades, resulting in changes to the design and/or requirements. This paper will address some of the key integration issues and results, including the Orion-to-Ares shared compartment venting and purging, Orion-to-EVA suit loop integration issues with the suit system, Orion-to-ISS and Orion-to-Altair intermodule ventilation, and Orion and Ground Systems impacts from postlanding environments.
\end{abstract}

\section{Nomenclature}

$c f m=$ cubic feet per minute

$\mathrm{CO}_{2}=$ carbon dioxide

$\operatorname{deg} F \quad=$ degrees Fahrenheit

$\mathrm{H}_{2} \quad=$ hydrogen

$\mathrm{kPa}=$ kilo Pascal

$\mathrm{m}^{3} \quad=$ cubic meters

$\mathrm{ppCO}_{2}=$ partial pressure of carbon dioxide

\section{Introduction}

$\mathrm{T}$

HE Environmental Control and Life Support and Thermal systems are distributed among the various elements of the Constellation Program as shown in Fig. 1. As indicated in the figure, there are many interfaces required to make the overall architecture work, and these interface requirements and designs have matured as the Constellation Program has progressed through its Preliminary Design Review (PDR) phase for the initial capability. A complete description of the architecture and interfaces can be found in the Constellation Program Architecture Description Document (ADD). ${ }^{1} \quad$ As the various elements and Program have matured through PDR, a number of issues have arisen relative to integration complexity, requiring fairly extensive analyses and testing. Four of the key integration issues are addressed here, and include purging/venting of the Orion-to-Ares shared compartment, integration of the Orion ECLS suit loop with the EVA suit system, intermodule ventilation between Orion and ISS, and Orion and Altair, and Orion postlanding environmental impacts and integration with Ground Systems. Resolution of these and other issues has contributed significantly to the success of the Program PDR.

\footnotetext{
${ }^{1}$ Orion Functional Area Manager for ECLSS and Crew Systems, Space Systems Department, ECLSS Branch/ES62, NASA Marshall Space Flight Center, AIAA Member.

${ }^{2}$ CxP Thermal/ECLS System Integration Group Co-Lead \& C3PO Advisory Team - Thermal/ECLS Lead, 2101 NASA Parkway, Mail Stop: EC6, AIAA Member.
} 


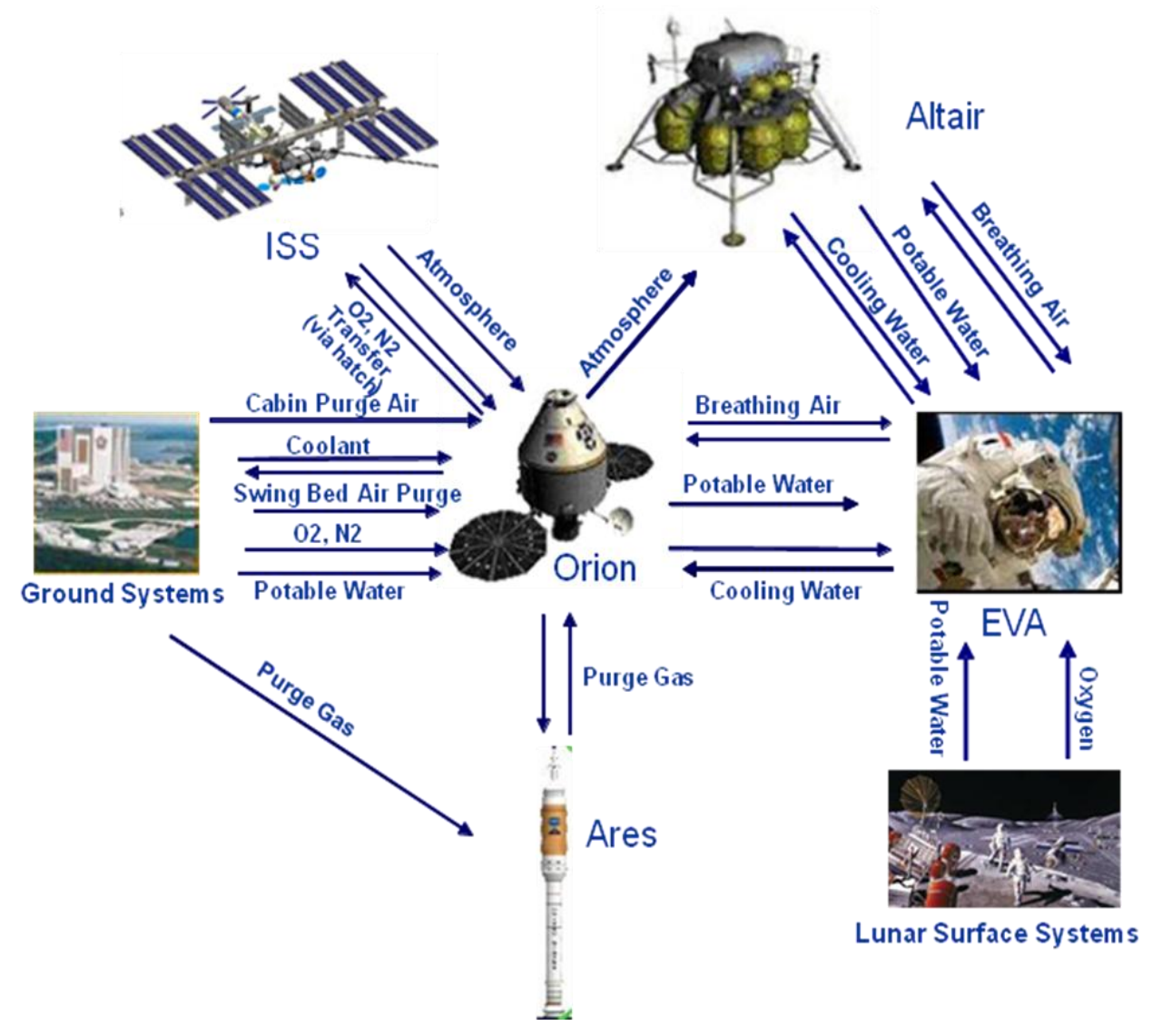

Figure 1. ECLSS and Thermal Interfaces Across Constellation Elements

\section{Orion-to-Ares Shared Compartment Venting and Purging}

The original design of the volume between the Orion Service Module (SM) and the Ares Upper Stage (US) included a seal between the Orion SM aft bulkhead and the Spacecraft conical adapter (SA). This seal effectively isolated the pre-launch purge environments of the SM and Ares Instrument Unit (IU). Because of difficulties with this seal design, this area was redesigned in early 2008 and the seal removed prior to the Orion Preliminary Design Review. Figure 2 is a cross section of the resulting shared volume as redesigned.

The new shared volume design presented an integration challenge resulting from several concerns including hazardous gas accumulation from the liquid hydrogen tank leakage into the shared volume, ascent venting and adequate vent area to prevent structural damage, and thermal impacts to the IU avionics boxes. In order to address these concerns, an analysis of the compartment including a detailed computation fluid dynamic (CFD) model was performed by the Purge and Hazardous Gas Leak Detection System team at NASA Glenn Research Center (GRC) and sponsored by the Ares I Vehicle Integration team and the Constellation ECLSS/Thermal Systems Integration Group (SIG). Results of the analysis addressing each area of concern are summarized as follows. A complete description of the analysis and results may be found in Ref. 2. 


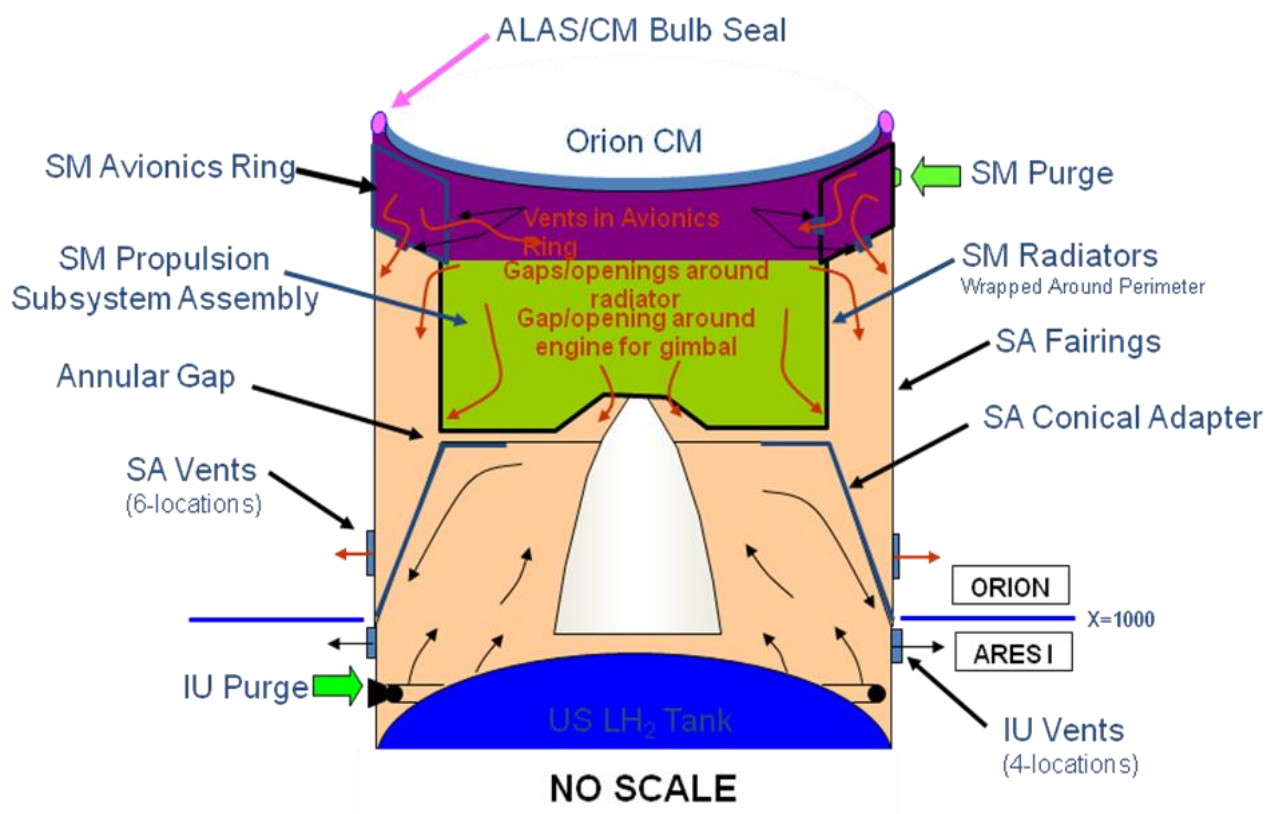

Shared Volume

Figure 2. Orion-Ares I Shared Compartment Configuration

\section{A. Hazardous Gas Accumulation and Detection}

The primary purpose of the purge flow within the IU is to control hazardous gas accumulation from the liquid hydrogen propulsion tank. The CFD analysis examined both the SM and IU purge velocities and cross mixing to determine the potential for hazardous gas accumulation. The results indicate that there is more than adequate flow velocities within the IU/SA volume and, even with a reduced Orion purge flow, there is considerable mixing in the SM upper volume. The study concluded that hazardous gas accumulation was not a concern for either the baseline or alternate vent design cases, which included various vent sizes, Orion-only and Ares-only locations. Second, the study examined whether the placement of the hazardous gas detection system at the IU vent exit would be adequate for a safe and conservative measurement of the hazardous gas. Because the highest $\mathrm{H}_{2}$ concentration exists in the IU volume, as long as purge flow exits the IU vents, the detection system will measure it. At a no cross-flow condition, at maximum spec $\mathrm{H}_{2}$ leak rates, the concentration of $\mathrm{H}_{2}$ at the IU vent exit will be $0.043 \%$. Any cross flow from Orion into Ares would reduce the $\mathrm{H}_{2}$ concentration in the IU, and any cross-flow from Ares into Orion would serve to dilute the $\mathrm{H}_{2}$ concentration in the Orion volume. For these reasons, the study concluded that the IU hazardous gas measurement design will safely and accurately measure the hazardous gas concentrations in the shared volume.

\section{B. Ascent Venting}

The NASA Marshall Space Flight Center (MSFC) Aerosciences Branch performed the ascent venting analysis. One of the primary goals of the venting analysis is to size vent openings to assure differential pressure is controlled during the ascent phase. Two baseline venting configurations were analyzed. The first configuration considered $0.039 \mathrm{~m}^{2}\left(60 \mathrm{in}^{2}\right)$ of vent area in Orion and $0.058 \mathrm{~m}^{2}\left(90 \mathrm{in}^{2)}\right.$ in Ares. The second configuration considered $0.058 \mathrm{~m}^{2}$ $\left(90 \mathrm{in}^{2)}\right.$ in Orion and $0.087 \mathrm{~m}^{2}\left(135 \mathrm{in}^{2}\right)$ in Ares. Comparisons of the two configurations were based on compartment-minus-freestream differential pressures and the predicted mass flow rates across the conical adapter. The differential pressure results indicated that compartment-to-freestream differentials exceeded $6.9 \mathrm{kPa}$ differential (1 psid) during ascent for the configuration with the smaller vents; whereas, the differential pressures did not exceed $6.9 \mathrm{kPa}$ differential ( $1 \mathrm{psid}$ ) for the larger vents. The mass flow rate profile characteristics were quite similar for both vent configurations considered. Analysis predictions indicated that flow during ascent was from Ares to Orion until Mach number approaching unity; after which, the flow was in the opposite direction. 
Further analysis also indicates that the area needed to keep the integrated compartment vented during ascent to the Orion limit of no more than 1 psid is more than the maximum vent area needed during on-pad purge operations to provide slight over-pressure in the compartment to prevent ambient air inflow through the Ares IU vents. These results are currently being reviewed between the Orion and Ares projects with forward work to resolve this issue.

\section{Thermal Effects on Ares Instrument Unit}

The avionics boxes housed within the Ares I IU are passively cooled through a combination of convection from the purge system, conduction to structure, and radiation to the hydrogen tank. Because of lack of design maturity, test data, and uncertainties associated with the purge system, it is not fully known whether this design will be adequate to maintain temperatures within box limits. In fact, the current thermal analysis predicts issues with approximately half of the boxes meeting thermal limits. Cross-flow of warmer SM purge gas into the IU only complicates these uncertainties, as the CFD analysis concluded a potential $1.6-4.2 \operatorname{deg} \mathrm{C}(2.9-7.6 \mathrm{degF})$ increase in temperature of the IU caused by 15-30\% mixing of warmer SM purge gas. As a potential risk mitigation, the Ares thermal team recommended modification of the Orion SM vents to bias flow toward the SM and away from the IU. Because of the lack of avionics box design maturity at the time of the Orion PDR, and the relatively low delta temperature increase predicted from the SM, the Orion Project was reluctant to incur cost to make these vent modifications. Further maturity of the design, along with testing to validate models and analytical predictions, is necessary, but may not result in compliance without additional modifications to the cooling scheme.

\section{Orion-to EVA Suit Loop Integration}

One of the more complicated interfaces for the Orion ECLSS is the atmosphere revitalization "suit loop" with the EVA suit. The suit loop serves to provide atmosphere revitalization $\left(\mathrm{CO}_{2}\right.$ removal, humidity control, cooling, and trace contaminant control) for either the habitable cabin volume when crew are unsuited, or for the suited crew environment for nominal or off-nominal suited operations. These operations include maintaining the cabin and suit loop at various operating pressures, making the design more challenging. Figure 3 provides a graphical comparison between the Apollo and Orion suit/suit-loop integrated designs. Key differences in the Orion design from Apollo include the addition of liquid cooling, a ganged connector with smaller diameter fluid lines to preclude a total umbilical size from being too unwieldy, a bidirectional umbilical connector feature with quick disconnects to facilitate EVA transfer of crew from Altair to Orion, and pressure swing absorption (PSA)-based $\mathrm{CO}_{2}$ and humidity removal instead of the Apollo lithium-hydroxide-based $\mathrm{CO}_{2}$ removal and a condensing heat exchanger.

\section{A. Pressure drop and the ARS fan design}

One of the major challenges in integrating the Orion ECLSS suit loop with the suit has been sizing the atmosphere revitalization system (ARS) fan for the many different flowrate/pressure drop/suit and cabin pressure cases covering the ISS and lunar missions, including EVA and unpressurized cabin operations. Initially, the fan was sized assuming a much smaller umbilical pressure drop than was eventually specified, resulting in a baseline ARS concept which provided a fan for open cabin operations and a separate, centrifugal blower for suited operations. To meet fault tolerance requirements, two fans of each type were needed, which presented significant packaging challenges. An alternate configuration of three fans of a common design able to meet all cases was more desirable for packaging and fault tolerance, but required a single fan motor design capable of operating over a wide range of aerodynamic conditions. Motor inefficiencies at certain operating points resulted in predicted heat losses exceeding that which could be dissipated by the baseline motor design, which included a metallic "can" to isolate the motor stator from the $100 \%$ oxygen environment. Options to reduce umbilical pressure drop by increasing umbilical size were not favorable to the crew. An innovative ceramic canned motor concept developed under a separate technology program funded by NASA was investigated as a possible solution and is shown in Fig. 4. Results of initial aerodynamic testing have shown that this concept will meet all the ISS and lunar suited and unsuited cases with acceptable motor losses. The EVA case will be able to be met with a modification to the motor into the existing housing. In addition, vibration testing of two ceramic liners of $0.635 \mathrm{~cm}$ and $0.89 \mathrm{~cm}(0.025$ " and 0.035 ") thicknesses at nominal and abort vibration profiles was performed. Both liners survived the testing without any evidence of structural damage or leakage. With this test result, work on an alternate uncanned motor option has been stopped. 


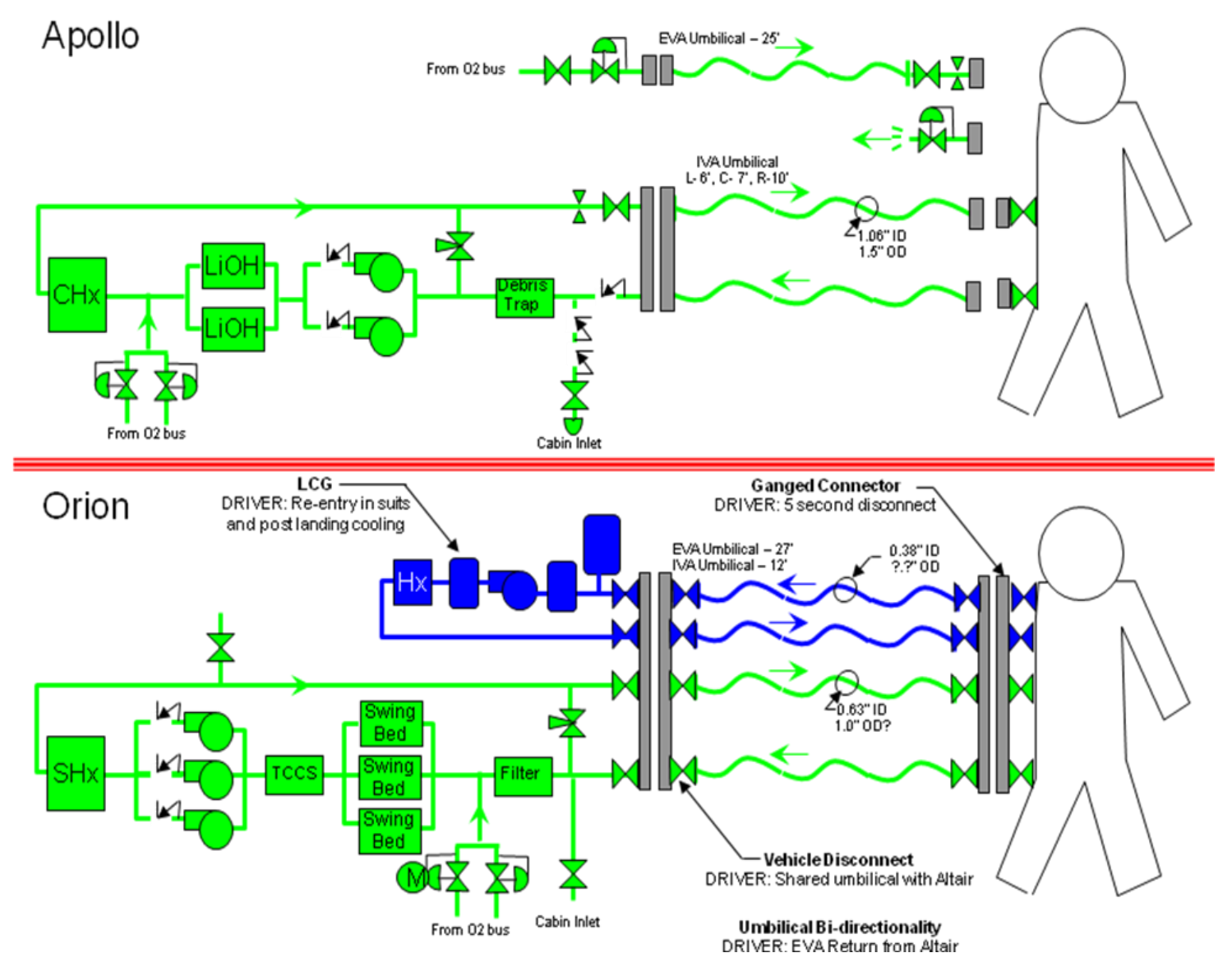

Figure 3. Comparison of Apollo and Orion ECLSS Suit Loop/Suit Designs

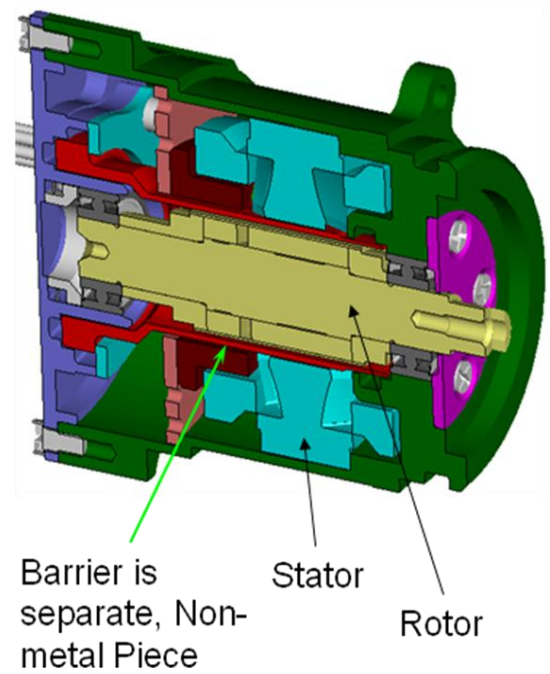

Figure 4. Ceramic Canned Motor

\section{B. Other suit/suit-loop integration issues}

In an effort to reduce the mass of the Orion vehicle, one of the two Liquid Cooling Garment (LCG) pumps in the original design was eliminated with the assumption that in case of failure of the single remaining LCG pump, airflow through the suit could provide adequate backup cooling. To confirm this assumption, an analysis was conducted as part of the Integrated Design Analysis Cycle (IDAC) using the NASA-developed Wissler human thermal model ${ }^{3}$ to predict crew core body temperature as a function of suit and environment conditions. This analysis showed that the nominal $0.127 \mathrm{~m}^{3} / \mathrm{min}(4.5 \mathrm{cfm})$ airflow through the suit is sufficient to prevent crew from overheating as long as the suit bladder material is somewhat permeable. ${ }^{4}$ An assumption of a Gortex-like material in this analysis is consistent with the current suit baseline.

Another issue currently in work pertains to the relative humidity inside the suit loop for suited operations. The PSA beds must remove both $\mathrm{CO}_{2}$ and humidity over a range of metabolic conditions. The partial pressure of $\mathrm{CO}_{2}$ must be kept below Human Systems Integration Requirements (HSIR) limits, while the relative humidity must be maintained above a minimum of $25 \%$ when averaged over a 24 -hour period for long duration suited operations, in order prevent discomfort from an environment that is too dry. A suit helmet design which retains some of the exhaled moist air around the crewmember's face helps ensure the minimum relative humidity can be 
met if the suit is provided with drier air from the ARS; however, such a helmet design is not as optimum for $\mathrm{CO}_{2}$ washout. Integrated analyses are still underway with the hope that a solution can be found which does not impact either the helmet or ECLSS ARS design.

Programmatically, the schedule for the Orion design has been significantly ahead of the suit design. This has required the integrated team to be proactive in adequately defining the interface requirements and assumptions. Integrated testing between the suit and suit loop with suited will be essential to retire risks and fully verify this interface prior to the first crewed flight. A dedicated testbed which will integrate early development, followed by qualification Orion ECLSS and EVA suit hardware with suited test subjects is planned and in the early buildup stages. This testbed will serve as a risk mitigation platform for early identification of issues, followed by formal qualification and verification of requirements not able to be tested in the Orion vehicle system test.

\section{Intermodule Ventilation}

Docked operations for both the International Space Station (ISS) and lunar missions require an air exchange between the Orion Crew Module (CM) and the ISS, and between the Orion CM and the Altair lander. For ISS docked ops, this allows crew to enter the quiescent Orion for periodic maintenance without having to fully power up the Orion atmosphere revitalization systems. For lunar transit, intermodule ventilation (IMV) allows crew to enter the Altair for equipment retrieval or other reasons, with the Orion providing atmosphere revitalization, thus saving Altair resources. Each of these interfaces has presented its own challenges and required unique solutions.

\section{A. ISS Docked Operations}

For ISS docked operations, the initial intermodule ventilation design concept allowed for Orion to dock at either the Pressurized Mating Adapter (PMA) at the Node 2 forward port, or the Node 1 nadir port as shown in Figure 5. Because the Node 2 forward port is currently the primary Shuttle Orbiter docking port, an assumption was made that the same integrated design could be utilized for the Orion; namely, that the Orion carry a "booster fan" to augment the suction flow provided by the ISS intermodule ventilation fan at that port. However, packaging and power compatibility issues for Orion made implementation of the Shuttle booster fan solution difficult. Also, the Node 1 nadir IMV interface on the ISS side is different from the Node 2 forward. Analysis by the Boeing Company showed that the Node 1 interface could be made to work with a slight modification of the ISS design, without requiring a booster fan on Orion. Further, analysis of the existing Node 2 IMV fan performance indicated that it could be made to provide adequate IMV flow by increasing the fan speed. However, before either of these solutions could be developed further, a programmatic decision was made to change one of the Orion docking ports from the Node 1 nadir to the Node 2 zenith (the Node 2 forward docking port remained unchanged). Since the Node 2 zenith port has no IMV fan on the ISS side of the interface, a different solution was necessary. It has been determined that the best overall solution is to use a common ISS IMV fan at both ports, providing a minimum of $2.7 \mathrm{~m}^{3} / \mathrm{min}$ (95 cfm) of ducted air for $\mathrm{CO}_{2}$ and humidity control, blowing into the Orion with return through the open hatch. A trade study examined three implementation options all utilizing existing IMV fan assets from ISS: package the fan and its associated mufflers in the ISS Node 2 for both ports, package this hardware in the Common Docking Adapter (CDA), or package the hardware within the Orion. Packaging the fan and mufflers within Orion proved very difficult, and was less desirable as the fan would either need to travel back and forth to Earth in Orion (representing a launch and landing weight penalty) or be removed and stowed on ISS prior to undocking. Packaging the fan and mufflers within the CDA appeared feasible, but also carried the issue with leaving the fan in an unpressurized environment for which it was not qualified between missions. The ISS program made the decision to do further study on the option of packaging the fans in Node 2 for both ports. In this option, the zenith port would be supported by re-ducting the existing Node 2 forward fan and the forward port would be supported by adding ducting and an IMV fan using available power and data scars, to the forward deck endcone (Fig. 6). 
D- Docking port

B-Berthing port

D2

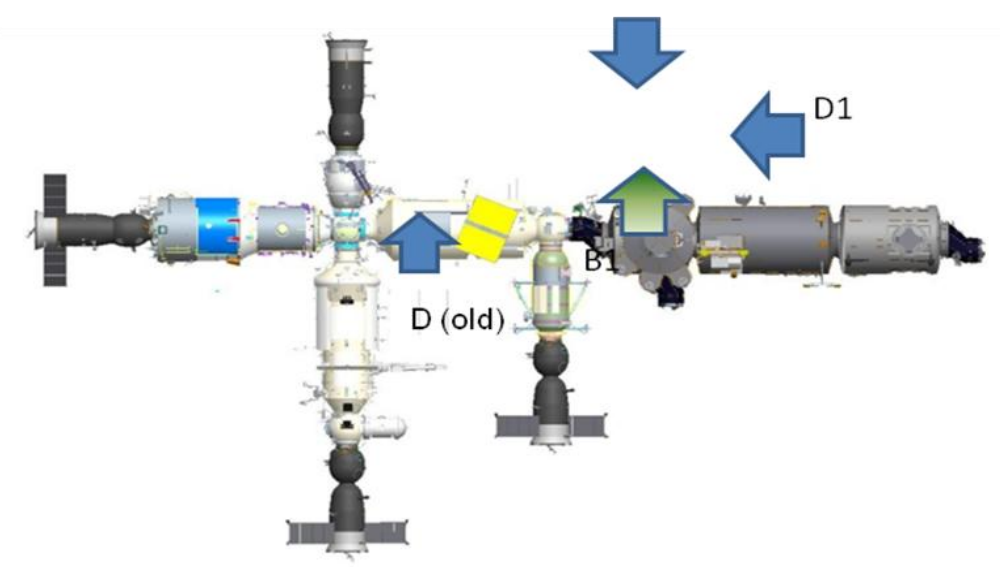

Figure 5. ISS Docking Location Change

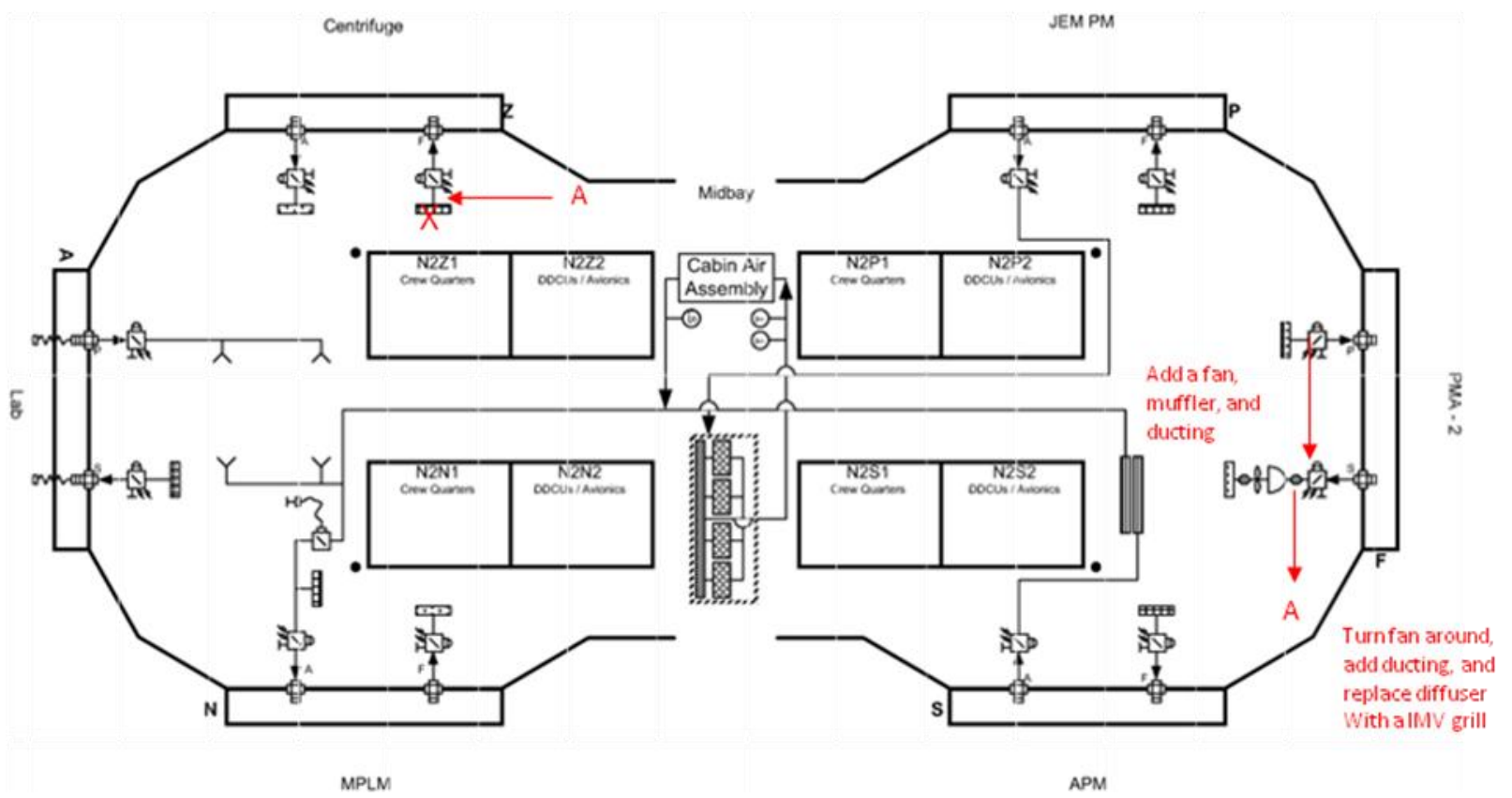

Figure 6. Reconfiguration of IMV Fans in Node 2 to Support Orion Docking

\section{B. Altair docked ops}

Although the only known operation requiring crew access to the Altair during lunar transit is initial retrieval of equipment launched in Altair, it is desirable to also have the flexibility to allow crew to enter the Altair for other reasons such as hardware inspection, privacy, or to allow more room for crew exercise in Orion. The parameter 
which drives the flowrate of the IMV is the need to keep the internal Altair atmosphere dewpoint below 8.9 degC (48 degF) to preclude condensation on cold surfaces. Analysis has shown that IMV flow sized to control humidity also controls $\mathrm{ppCO}_{2}$ well below its limits.

Providing IMV from the more-humid mixed Orion cabin environment requires much more flow than providing ducted IMV from downstream of the Orion $\mathrm{CO}_{2}$ and humidity removal system, which is cool, dry air at a dewpoint of $-23.3 \operatorname{deg} C(-10 \mathrm{degF})$. Ducting this relatively small airflow directly from the Orion ARS using the motive force of the ARS fan was determined to be more feasible than providing a higher flowrate from the mixed cabin air. Analyses were performed to determine what flowrate at these conditions would be required for various numbers of crew and length of time within Altair. Figure 7 shows the analysis results for two candidate flowrates: 0.28 and $0.42 \mathrm{~m}^{3} / \mathrm{min}(10$ and $15 \mathrm{cfm})$. As indicated by the plot, in order to maintain the dewpoint in Altair below $8.9 \mathrm{degC}$ (48 degF), a $0.28 \mathrm{~m}^{3} / \mathrm{min}(10 \mathrm{cfm})$ flowrate allows a maximum of 2 crew to ingress Altair for approximately 90 minutes; however, at a flowrate of $0.42 \mathrm{~m}^{3} / \mathrm{min}(15 \mathrm{cfm}), 3 \mathrm{crew}$ may ingress for one hour and $2 \mathrm{crew}$ may ingress for an indefinite amount of time, providing greater operational flexibility during lunar transit.

Providing $0.42 \mathrm{~m}^{3} / \mathrm{min}(15 \mathrm{cfm})$ vs. $0.28 \mathrm{~m}^{3} / \mathrm{min}(10 \mathrm{cfm})$ of IMV flow was initially believed to represent an impact to the Orion design. However, maturation of the Orion ARS design has indicated that $0.42 \mathrm{~m}^{3} / \mathrm{min}(15 \mathrm{cfm})$ can be provided with no impact, with the understanding that IMV with Altair will not be required during crew sleep periods when the ARS fan flowrate is reduced to accommodate lower metabolic rates.

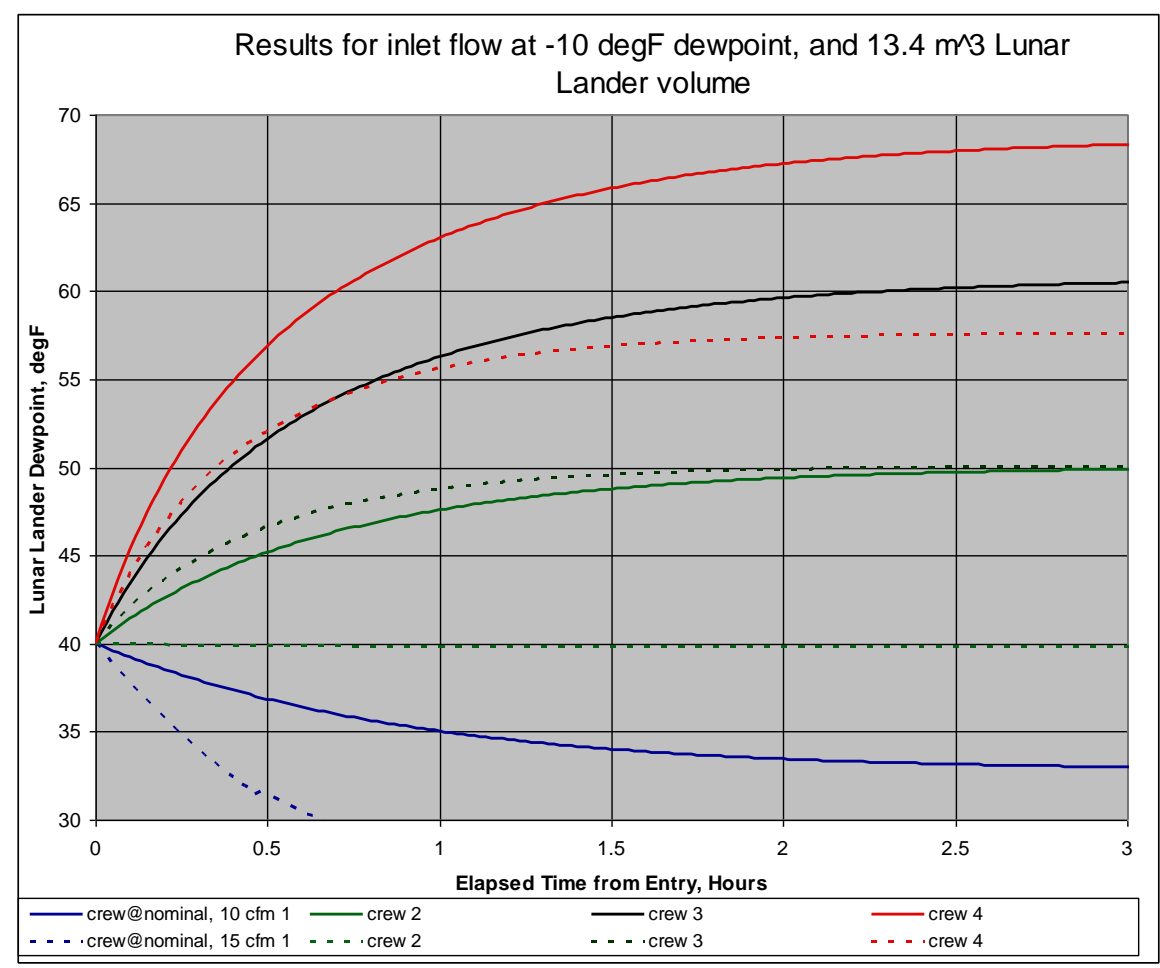

Figure 7. Orion IMV flowrate effect on dewpoint within Altair for various crew sizes and ingress times.

\section{Postlanding Impacts and Ground Systems Integration}

The concept of operations for Orion landing and recovery involves the vehicle with crew suited re-entering Earth's atmosphere with a nominal water landing near San Clemente, CA. After landing, the crew remains suited with LCG cooling provided by vehicle ammonia boiling for two hours until ground crew arrives, secures the vehicle on the ship, and opens the hatch. In an off-nominal landing situation with ground rescue potentially taking longer than two hours, a snorkel fan can be activated providing circulation of outside air with the crew cabin, once ammonia cooling is depleted. Depending on the outside temperature of the off-nominal landing location, the crew may need to doff suits to keep from overheating until rescue forces arrive. This entire operations concept and design solution was the result of a significant analysis and integration effort over the past two years, combining passive and 
active thermal analysis of the Orion vehicle for re-entry and postlanding, thermal modeling of the crew themselves in the cabin and suited environments, analysis of landing sites and associated environmental conditions, trajectory analysis to determine possible off-nominal landing locations, and ground rescue and recovery assessments. This section will summarize the analysis and key findings, focusing primarily on the thermal analysis.

The thermal analysis conducted was threefold. The vehicle passive thermal model was used to combine the effects of re-entry heating and postlanding solar heating on the vehicle. These inputs were used in a cabin thermal model to predict resulting internal cabin air temperatures and humidity, including effects of external air exchange with the environment. Finally, the human thermal analysis utilizing the Wissler Human Thermal Model $^{5}$ determined the resulting crew core body temperature for given suited, unsuited, and cabin conditions. The analysis also takes into account various crew metabolic loads considering possible seasickness. Early design cycles showed that for a nominal landing at San Clemente, crew core body temperature can be maintained below the required $38 \mathrm{degC}(100.5$ degF) limit for cognitive deficit until rescue with the crew remaining suited and the only cooling provided via outside air exchange with a snorkel fan flowrate of $4.25 \mathrm{~m}^{3} / \mathrm{min}(150 \mathrm{cfm})$. However, additional cooling was required for off nominal landing sites in order to allow the crew time to remove their suits before an extended period of snorkel fan cooling only. For off-nominal landing, the most extreme case considered was a Western Equatorial Pacific (WEP) landing site. For such a site, with snorkel fan cooling alone (no LCG cooling), core body temperature is exceeded in roughly one hour if the crew remains suited. Early concepts studied options to provide active cooling for the entire 24-hour contingency rescue window, so that the crew would not need to doff suits, but these options were weight and power-prohibitive and required technology development. For this reason, the operations concept and design solution adopted required the vehicle to carry an additional 2 hours of ammonia cooling post landing in order to allow the crew time to doff suits. The 2 hours of cooling will also be utilized during the nominal landing case, so that crew can remain at a more comfortable temperature while suited and awaiting rescue.

The latter design cycles have been primarily focused on the ability to support suit doffing in off-nominal hot landing conditions. The effort to doff and help others doff suits is reflected in the metabolic profiles used in the model, and also assumes that the first crew to doff suits can remain in their LCG's connected to the coolant loop until all crew are out of suits and air exchange via the snorkel fan can be initiated. Prior to snorkel fan flow initiation, ammonia cooling is terminated so that the crew is not exposed to vented ammonia vapor. Various landing time of day cases were also considered as they affect solar heating on the vehicle. Figure 8 is a summary of the latest analysis results for the hot water landing site. In this figure, results labeled "DAC 2" show the core temperature violations that were a concern early on. In the last design cycle, the solar incident radiation was updated to reflect a more realistic ocean based incident heating. As seen by the plots labeled "Core Temp 2-4" this change has resulted in significant reduction in the core body temperature such that the maximum core body temperature predicted for this scenario is just over $37.2 \operatorname{degC}(99 \mathrm{degF})$ during the transient suit doffing period but then returns to a more or less steady temperature of less than $37.2 \operatorname{degC}(99 \mathrm{degF})$ for the remainder of the recovery period.

The postlanding study will be revisited for the Orion Critical Design Review with not only the latest thermal analysis but also revised predictions of off-nominal landing sites and trajectory analysis, and recovery time projections by Ground Operations. The most challenging cases involve deconditioned (by microgravity) crew returning either from the ISS or Exo-LEO missions, who will be challenged to doff suits within the 2-hour active cooling period. The initial 2008-2009 study concluded that mission scenarios involving off-nominal landing in a warm location where ground forces are greater than 2 hours away were highly unlikely but this will be re-assessed. 


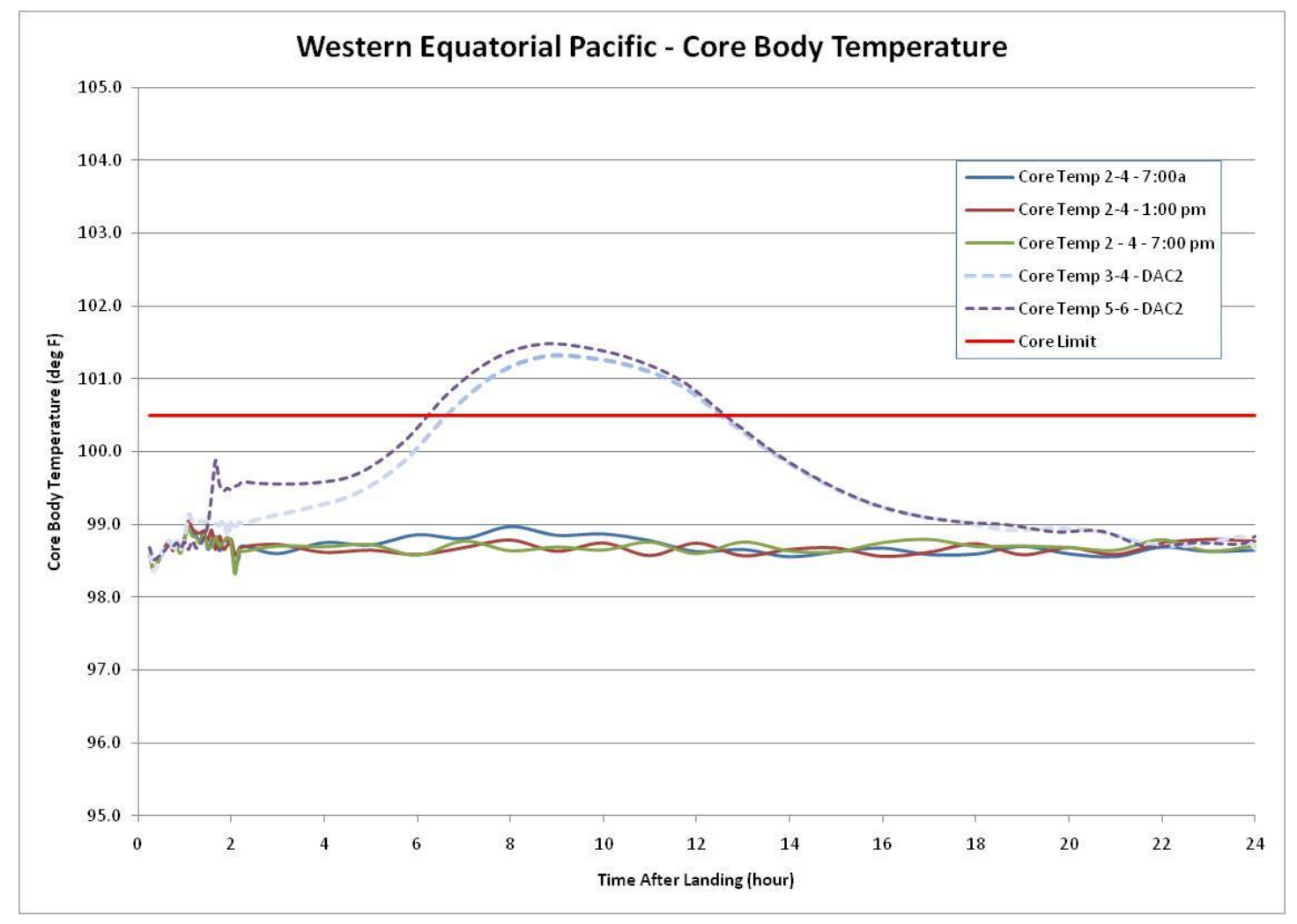

Figure 8. Postlanding Core Body Temperature for Nominal and Off-Nominal Landing Locations

\section{Conclusion}

This paper has addressed just four of the key issues resolved through integrated analysis and design work in the ECLSS and Thermal areas through the Constellation initial capability PDR milestone. Lessons learned from the initial capability phase can be applied as the program matures through the critical design review phase, and onto the lunar capability phase.

\section{Acknowledgments}

R. L. Carrasquillo and D. E. Williams thank the following individuals for specific contributions to this publication: Carol Tolbert from the NASA Glenn Research Center, Cynthia Cross, John Lewis, and Grant Bue from the NASA Johnson Space Center, and Will Downs from the NASA Marshall Space Flight Center.

\section{References}

1"Constellation Program Architecture Description Document", CxP 70077, Revision C, May 21, 2010.

${ }^{2}$ Edwards, D., Frankenfield, B., and Stewart, M., “Ares I-Orion Shared Purge Volume Flow Analysis Final Report”, NASA Glenn Research Center, Report GRC-PHG-ANL-020, Cleveland, OH, April 30, 2009.

${ }^{3}$ Bue, G., Kesterson, M., and Trevino, L., "Wissler Simulations of a Liquid Cooled and Ventilation Garment for Extravehicular Activity", SAE 2006-01-2238, 36 ${ }^{\text {th }}$ International Conference on Environmental Systems, Norfolk, VA, July 2006.

${ }^{4}$ Bue, G., "Human Thermal Modeling", Final Report, TDS SIG-06-1015, https://ice.exploration.nasa.gov/cait/tdsheets/show_form/1829 